\title{
UV Aging Effects on Polycarbonate Properties
}

\author{
S. Redjala $\cdot$ N. Aït Hocine $\cdot$ R. Ferhoum $\cdot$ M. Gratton $\cdot$ N. Poirot $\cdot$ S. Azem
}

Submitted: 15 April 2020/in revised form: 21 July 2020/Published online: 16 September 2020

(C) ASM International 2020

\begin{abstract}
This work deals with the effects of ultraviolet (UV) aging on polycarbonate (PC) properties. Thus, a PC was subjected to accelerated UV radiation with a wavelength range from 200 to $280 \mathrm{~nm}$, at different times. Induced changes in the material were studied by UV-visible spectrophotometry, Fourier transform infrared (FTIR) spectroscopy and X-ray diffraction. The material surface was analyzed by optical microscopy (OM) and scanning electron microscopy (SEM). Microhardness and uniaxial tension tests were performed on the aged and no-aged materials. It appeared that the studied PC turns yellow with UV aging time, in agreement with UV-visible spectrophotometry results that highlighted a loss in transparency of the aged material. The microhardness measurements showed that PC samples were entirely affected by UV radiations. In addition, the material performances in uniaxial tension dropped with UV aging. The decrease in PC mechanical properties was related to the rupture of the most vulnerable bonds, revealed by FTIR analyses, and to superficial cracks showed by OM and SEM micrographics.
\end{abstract}

S. Redjala $\cdot$ N. Aït Hocine - M. Gratton

INSA CVL, Univ. Tours, Univ. Orléans, LaMé, 3 Rue de la Chocolaterie, BP 3410, 41034 Blois Cedex, France

S. Redjala $\cdot$ R. Ferhoum $\cdot$ S. Azem $(\bowtie)$

Département de Génie Mécanique, Université Mouloud

Mammeri, BP 17, Tizi-Ouzou 15000, Algeria

e-mail: azemsaid@yahoo.fr

N. Poirot

GREMAN, IUT de Blois, 15, rue de la chocolaterie, 41000

Blois, France
Keywords Polycarbonate - Aging · Ultraviolet . Physical properties $\cdot$ Mechanical properties

\section{Introduction}

In comparison with metal and inorganic materials, polymers show some advantages, such as lightweight, high strength, anti-rust, and they are easily processable. However, these materials degrade under temperature variations, exposure to rain or sunlight and in the water or oils. Polymer materials are applicable for various purposes needing weight reduction, vibration isolating and damping, coating and covering, heat insulation. They are used in interior and exterior parts of automobile, railway vehicle, airplane, shipbuilding, commodities, housewares, pipelines for transportation of potable and wastewater, electrical appliances and toys.

Polycarbonate (PC) is a polymer widely used in optical, medical, electronic and spatial applications, and for the preparation of nanotubes and nanowires [1-6]. Its high impact resistance makes it an important component in many devices, such as smartphones, tablets, computers. Because of its transparency, it is also used in windshields, roofs, greenhouses, security screens and in LED technology.

Several studies have been done on polymers ultraviolet (UV) aging [7-12]. It was reported by Tse [7] that during UV irradiation, molecules are excited and processes of chain breakage and cross-linking occur. Firstly, the main chains undergo a photodissociation revealed by El Ghazaly [9], and then free radicals, such as "phenoxy (C6H5O), phenyl (C6H5-R)" which appear as small separate molecules, are formed [12]. The cross-linking can occur during 
free radical migration, resulting in recombination with other radicals or with principal chains [9, 10]. Some physicochemical properties of macromolecules are then considerably modified $[8,10,11]$. In bisphenol A polycarbonate, photodegradation was attributed to two different mechanisms: photo-Fries rearrangement and photooxidation. These reactions are initiated following the break of covalent bonds caused by energy absorption [13]. The relative importance of these mechanisms depends on the irradiation wavelengths, as attested by Rivatonet al. [14] and Torikai et al. [15]. It was shown by El Ghazalya and Alzahrani [11], and Aggourand Aziz [12] that when the irradiation wavelengths present in the Earth's sunlight are used for degradation, the photooxidation reaction is more significant than the photo-Fries rearrangements. One mechanism predominates over the other, depending on the wavelength of the incident radiation [14-16].

Photo-Fries reaction is favored by short wavelength radiation and does not need oxygen to occur. In this mechanism, the energy absorbed by the material promotes the break of the carbonate bonds, forming two primary free radicals [17] which rearrange to form phenylsalicylates and hydroxybenzophenones, as well as other groups such as dihydroxybiphenyl and hydroxydiphenyl ether groups. The oxidation of these groups produces substances like orthodihydroxybenzophenone or diphenoquinone which are responsible for the yellowing observed in photodegraded samples, as found by Clark et al. [18]. The products formed during photo-Fries reactions can also be photooxidized, giving secondary and tertiary products of lower molecular weight. Factor and Chu [19] indicated that photooxidation is a more important reaction pathway in the photoaging of polycarbonate than the photo-Fries reaction.

In the photooxidation, the UV radiation is absorbed by the impurities of the polymer, and the hydrogen atoms are extracted from the methyl groups $(-\mathrm{CH} 3)$, forming a free radical and thereby initiating a chain scission process that propagates the reaction. In the presence of oxygen, the methyl side chains are photooxidized as hydroperoxide intermediates that are converted into tertiary alcohols and ketones. Another photooxidation of the products and aromatic rings also contributes to the yellowing of the polymer.

The present work is devoted to the understanding of the structural changes in a PC, during the UV irradiation, and the resulting effects on its physical and mechanical properties. The chemical modifications occurring in the material were examined by the Fourier transform infrared spectroscopy (FTIR). Material transparency was checked by UV-visible spectroscopy and the change in crystallite size was evaluated by X-ray diffraction (XRD). In addition, effects of UV aging on the material mechanical properties were quantified, in relation to microstructure changes observed by scanning electron microscopy (SEM).

\section{Experimental Investigations}

\section{Material}

The PC used in the work was provided by SABIC PLASTICS Company from Algeria, in form of sheets of $2 \mathrm{~m} \times 1 \mathrm{~m}$ and a thickness of $4.5 \mathrm{~mm}$. Generally, PC is an amorphous polymer but can have a nanocrystallinity induced during its elaboration. In addition, it is transparent, with good impact resistance and low density $(\rho=1.2 \mathrm{~g} /$ $\mathrm{cm}^{3}$ ). Its glass transition temperature, $T_{\mathrm{g}}$, is of about $145{ }^{\circ} \mathrm{C}$. Its chemical structure $\mathrm{C}_{16} \mathrm{H}_{14} \mathrm{O}_{3}$ is shown in Fig. 1 .

\section{UV Aging Procedure}

The samples were exposed to ultraviolet (UV) radiation, in an experimental enclosure equipped with two Philips T8 $25 \mathrm{~W}$ lamps mounted in parallel under its vault. The irradiation intensity is $88 \mu \mathrm{W} / \mathrm{cm}^{2}$ at $1 \mathrm{~m}$ from the source. The inner walls of the enclosure were covered with aluminum foil. A ventilation system maintained the sample's temperature at $25{ }^{\circ} \mathrm{C}$ while near the lamps it reached $40{ }^{\circ} \mathrm{C}$ in the absence of ventilation. Specimens cut from a large sheet of $2 \mathrm{~m} \times 1 \mathrm{~m} \times 4.5 \mathrm{~mm}$ were placed on a shelf, at $10 \mathrm{~cm}$ from lamps that emit UV radiation with a wavelength range from 200 to $280 \mathrm{~nm}$. Aging times were 72, 144 and $216 \mathrm{~h}$. The sample face directly exposed to the UV radiation is called "exposed face" (EF), and the face in contact with the shelf is called "no-exposed face" (NEF).

\section{Characterizations}

\section{UV-Visible Spectrophotometry}

Absorbance and transmittance properties of the virgin and aged PC were evaluated with a spectrophotometer, using visible ultraviolet ray. The beam passes through the sample and falls on a photocell that records its intensity.

The transmittance $T$ is considered as the ratio of the transmitted ray intensity $I$ to the incident ray intensity $I_{0}$ :

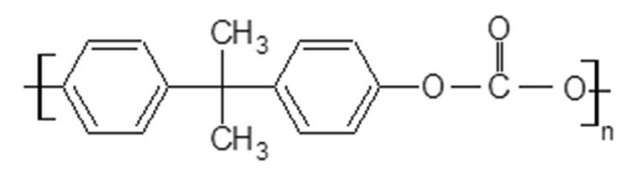

Fig. 1 Chemical structure of PC 
$T(\%)=\frac{I}{I_{0}} 100$

(Eq 1)

The absorbance $A$ is given by the following equation:

$A=-\log T=\log \left(\frac{I_{0}}{I}\right)$

\section{Fourier Transform Infrared Spectroscopy}

Virgin and aged materials were analyzed using a PERKIN ELMER Fourier transform infrared (FTIR) spectroscopy, in transmission mode, with a resolution of $2 \mathrm{~cm}^{-1}$, in a scanning range of $450-4000 \mathrm{~cm}^{-1}$, with 25 scans.

The sample is taken by scratching it on the surface of the sample directly exposed (EF) to UV radiation. One milligram of powder is mixed with $75 \mathrm{mg}$ of potassium bromide $(\mathrm{KBr})$ in a mortar in order to homogenize the mixture. A small quantity of this mixture is poured into the body of a stainless steel pelletizer closed on both sides by two screws. One of the screws is tightened using a wrench to obtain a thin patch transparent to infrared radiation. After compression, the two screws are removed from the body of the pelletizer which will be placed in the device so that the infrared beam passes through the sample. The transmitted signal will be directed to a detector and processed by Fourier transform to obtain a plot of the intensity spectrum as a function of the wave number.

\section{$X$-ray diffraction}

The samples were analyzed with a Bruker D8 Advance Xray diffractometer, with an assembly $\theta-2 \theta$. This diffractometer is equipped with a high voltage generator of $40 \mathrm{kV}$, which accelerates the electrons in the X-ray tube at the copper anode whose line $K_{\alpha}$ is of $1.54 \AA$. The scanning interval was between $5^{\circ}$ and $80^{\circ}$, with a step of $0.02^{\circ}$ and an exposure time of $1 \mathrm{~s}$ per step.

\section{Microhardness}

The microhardness of no-aged PC and aged PC was measured, according to ASTM E 384-99 norm, using samples of $10 \times 10 \times 4.5 \mathrm{~mm}^{3}$. Measurements were made on EF and NEF of specimen, as well as along the sample thickness ranging from EF to NEF. The device used was a THV501 Micro-Vickers tester, equipped with an optical microscope and a diamond pyramid indenter with an angle of $136^{\circ}$ at the top.

A load $P=2.94 \mathrm{~N}$ was applied for $30 \mathrm{~s}$, and the two diagonals of the indenter imprint were measured, and their average value $d$ was calculated. Microhardness was then calculated from the following equation:
$\mathrm{HV}=0.1854 \times \frac{P}{d^{2}}$

Each microhardness value is an average of five measurements.

\section{Tensile Tests}

Tensile tests were carried out on all the studied materials, using a machine MTS-Model 43 equipped with a load cell of $10 \mathrm{kN}$. Normalized specimens, according to ASTM D638 standard, were tested. However, to ensure the break in the central zone of these specimens, their dimensions were optimized using finite element method (FEM), with SolidWorks software (Fig. 2). The samples were machined from large sheet with suitable milling machine.

The tests were conducted until the total rupture of the sample, at a strain rate of $0.0012 \mathrm{~min}^{-1}$. Longitudinal and transversal deformations were calculated from displacements of four circular spots previously placed in the specimen central zone. These displacements were measured with a CDD camera.

\section{Microstructural Observation}

Microstructures of virgin and aged PC were observed using Olympus BX60 optical microscope (OM), with magnification up to 1000, and TESCAN MIRA3 scanning electron microscope (SEM), with an acceleration voltage of $10 \mathrm{kV}$ and secondary vacuum of $10^{-7}$ torr. As the PC is an electrical insulator, a gold layer was deposited on the surfaces to be observed with GEOL type gold evaporator, to inhibit charging. The micrographs were obtained in secondary electron (SE) and backscattered electrons (BSE) modes, with different magnifications.

\section{Results and Discussion}

\section{Transparency}

Figure 3 shows an increase in yellowing aspect of the aged materials, i.e., a loss of their transparency, as the UV exposure time growths. This yellowing is the result of a

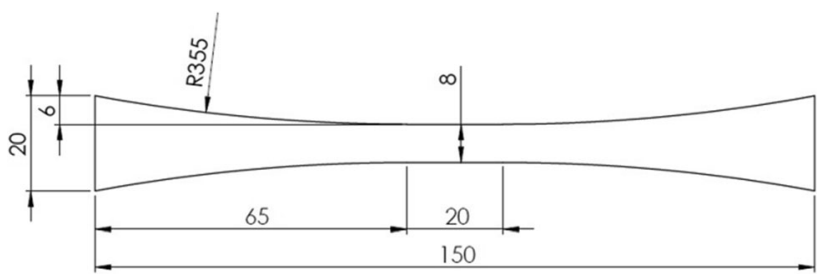

Fig. 2 Tensile specimens 
reaction sequence caused by UV radiation. The absorption of UV energy by PC macromolecules causes a rupture of the most vulnerable bonds and a formation of radicals that can oxidize in presence of the oxygen. This mechanism is at the origin of the formation of substances such as orthodihydroxybenzophenone or diphenoquinone which are responsible for the yellowing observed in the aged samples [18].

\section{UV-Visible Spectrophotometry}

Figure 4 shows zero transmittance up to the wavelength near to $380 \mathrm{~nm}$ where the absorbance decreases sharply, while the transmittance increases suddenly. Beyond this wavelength value, the virgin PC has a transmittance of about $80 \%$ while the aged PC shows lower transmittance and higher absorbance, as the aging time increases, with no significant changes between $144 \mathrm{~h}$ and $216 \mathrm{~h}$ of UV exposure. It is worth mentioning that the curves of the four samples show the same trends.

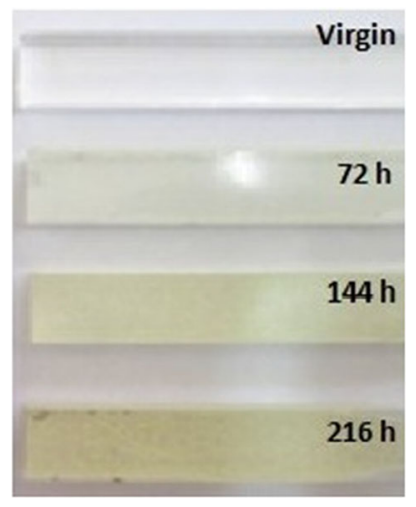

Fig. 3 Transparency of the virgin and aged materials

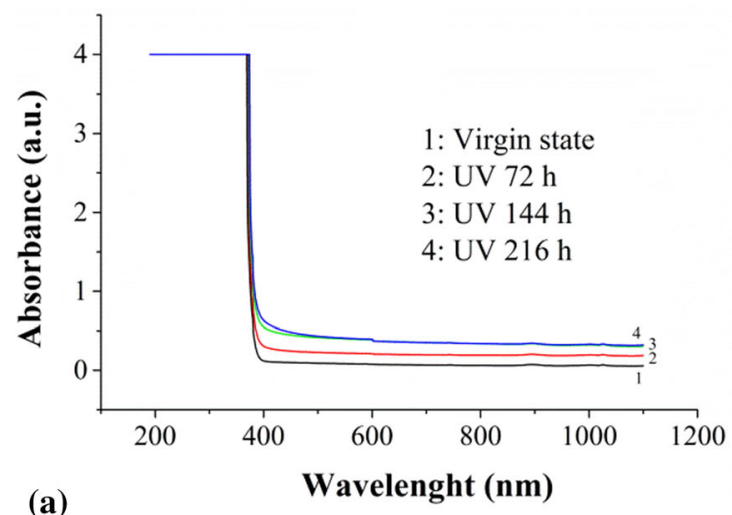

Fourier Transform Infrared Spectroscopy

FTIR spectra of no-aged and aged materials are reported in Fig. 5. The FTIR spectrum of the virgin PC reveals the main bonds that form the molecular architecture of this material, such as double bonds carbon $=$ carbon $(\mathrm{C}=\mathrm{C})$, carbon $=$ oxygen $(\mathrm{C}=\mathrm{O})$, as well as the mono-bonds carbon-carbon $(\mathrm{C}-\mathrm{C})$ and carbon-hydrogen $(\mathrm{C}-\mathrm{H})$. More generally, Fig. 5 shows the functional groups of polycarbonate that are methyl, phenyl, carbonyl and hydroxyl groups. The infrared absorption bands of these groups are listed in Table 1, in accordance with the literature [20].

FTIR spectra indicate that the studied PC undergoes many structural changes during aging, as highlighted by the modifications of some absorbance peaks. Indeed, Fig. 5 shows a decrease in absorbance in the vicinity of $1000 \mathrm{~cm}^{-1}$, for the aged materials, which is attributed to the stretching of the carbonate resulting in the dissociation of the molecular chain. This outcome is in agreement with those reported in the literature explaining that the breaking of carbonate bonds leads to release of carbon monoxide (CO) or carbon dioxide $\left(\mathrm{CO}_{2}\right)$ [21]. Also, the breaking of the carbonates bonds allows the formation of free radicals, such as phenoxy (C6H5O-) and phenyl (C6H5-R), which appear as small separate molecules [12] that can migrate and recombine between themselves or with other molecular chains $[9,10]$. Moreover, the absorbance peak height of the $\mathrm{C}=\mathrm{O}$ bonds, at $1780 \mathrm{~cm}^{-1}$, decreases with aging time [22]. A decrease in the peak intensity of aromatic $\mathrm{C}-\mathrm{H}$, at $2972 \mathrm{~cm}^{-1}$, is observed, while the band intensity of aliphatic $\mathrm{CH}_{3}$, at $1405 \mathrm{~cm}^{-1}$, remains almost constant. The decrease in absorbance observed for the $\mathrm{C}-\mathrm{H}$ bond is due to the abstraction of the hydrogen atom during the first step of the photooxidation process [23]. The vibration band observed around $3500 \mathrm{~cm}^{-1}$ is attributed to intramolecular bonded $\mathrm{OH}$ groups of rearrangement products [17]. Finally, it is worth mentioning that the $\mathrm{C}=\mathrm{C}$ double bonds of the $\mathrm{PC}$

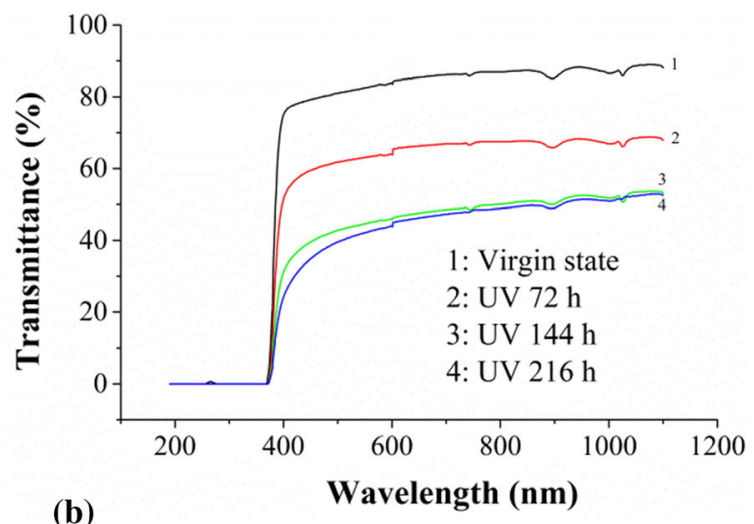

(b)

Fig. 4 Absorbance (a) and transmittance (b) spectra of PC, before and after UV aging 
Table 1 Chemical bonds of virgin PC

\begin{tabular}{lc}
\hline Chemical bonds & Wavelength $\left(\mathrm{cm}^{-1}\right)$ \\
\hline $\mathrm{C}-\mathrm{O}-\mathrm{C}$ & 1004 \\
$\mathrm{CH}_{3}$ & 1405 \\
$\mathrm{C}=\mathrm{C}$ & 1571 \\
$\mathrm{C}=\mathrm{O}$ & 1780 \\
$\mathrm{C}-\mathrm{H}$ & 2972 \\
$\mathrm{O}-\mathrm{H}$ & 3500 \\
\hline
\end{tabular}

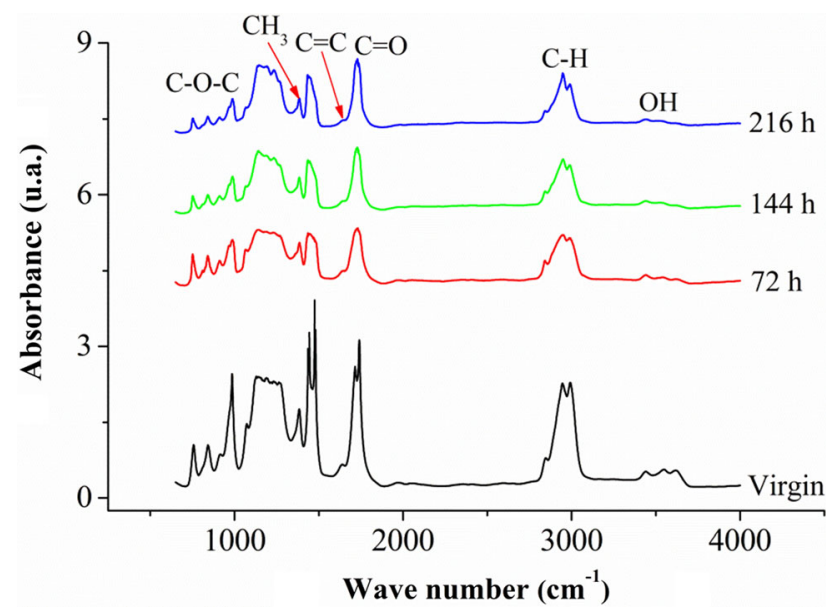

Fig. 5 FTIR absorbance spectra of aged and no-aged PC

Table 2 Characteristics of XRD peaks

\begin{tabular}{lcccc}
\hline Peak & $\begin{array}{c}\text { Diffraction } \\
\text { angle } 2 \theta\left(^{\circ}\right)\end{array}$ & $\begin{array}{c}\text { Intensity } \\
\text { I (u.a) }\end{array}$ & $\begin{array}{c}\text { Intermolecular } \\
\text { distance in } \\
\text { crystallites }(\AA)\end{array}$ & $\begin{array}{c}\text { Average size of } \\
\text { crystallites D } \\
(\mathrm{nm})\end{array}$ \\
\hline 1 & 13.63 & 26.20 & 6.80 & 2.80 \\
2 & 30.33 & 5.34 & 2.94 & \\
3 & 41.53 & 2.02 & 2.17 & \\
\hline
\end{tabular}

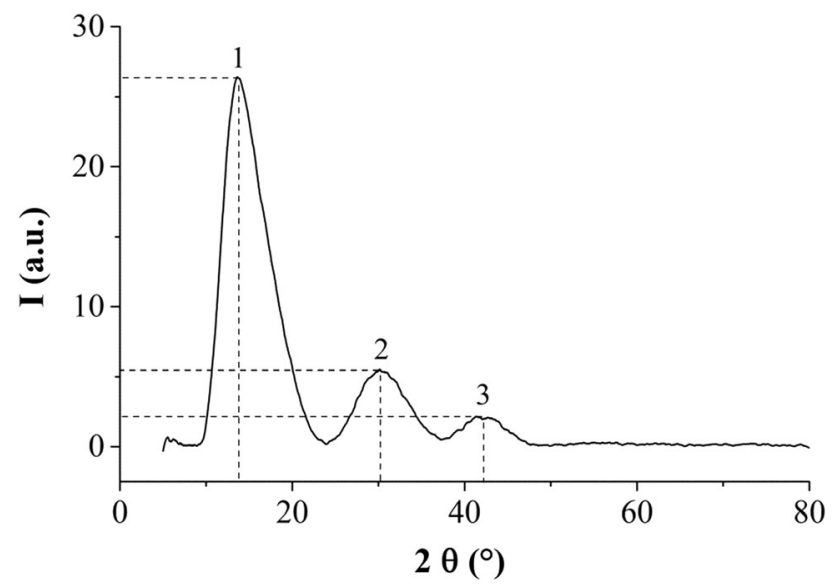

Fig. 6 Diffractogram of the virgin PC
Table 3 Characteristics of the first XRD peak for all aging times

\begin{tabular}{lcccr}
\hline \multicolumn{5}{c}{ Peak 1} \\
\hline Aging times & $0 \mathrm{~h}$ & $72 \mathrm{~h}$ & $144 \mathrm{~h}$ & $216 \mathrm{~h}$ \\
\hline Angle $2 \theta\left(^{\circ}\right)$ & 13.63 & 15.08 & 15 & 15.15 \\
Intensity $I($ a.u $)$ & 26.20 & 36.8 & 2.91 & 40.40 \\
Distance $d_{\text {hkl }}(\AA)$ & 6.48 & 5.86 & 5.89 & 5.03 \\
Crystallite size $D(\mathrm{~nm})$ & 2.80 & 3.00 & 3.3 & 3.00 \\
\hline
\end{tabular}

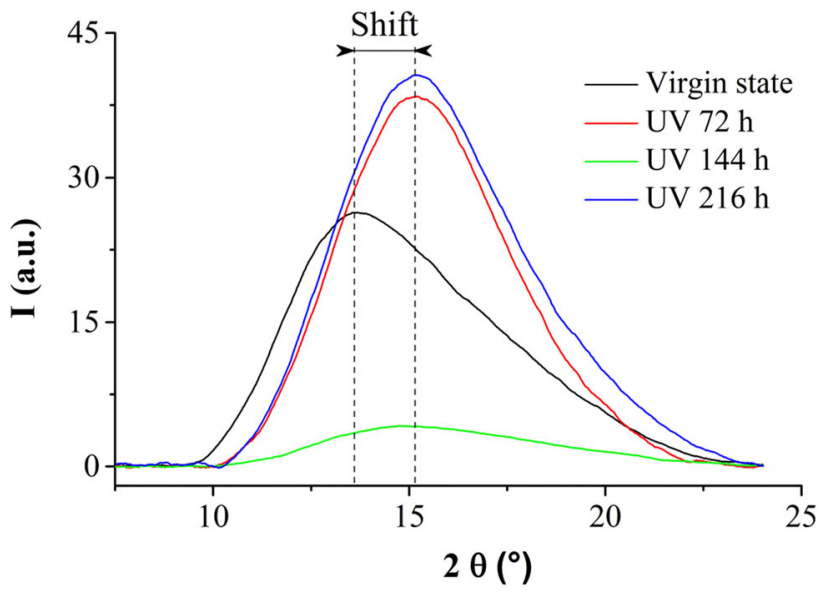

Fig. 7 First diffraction peak as a function of UV aging time

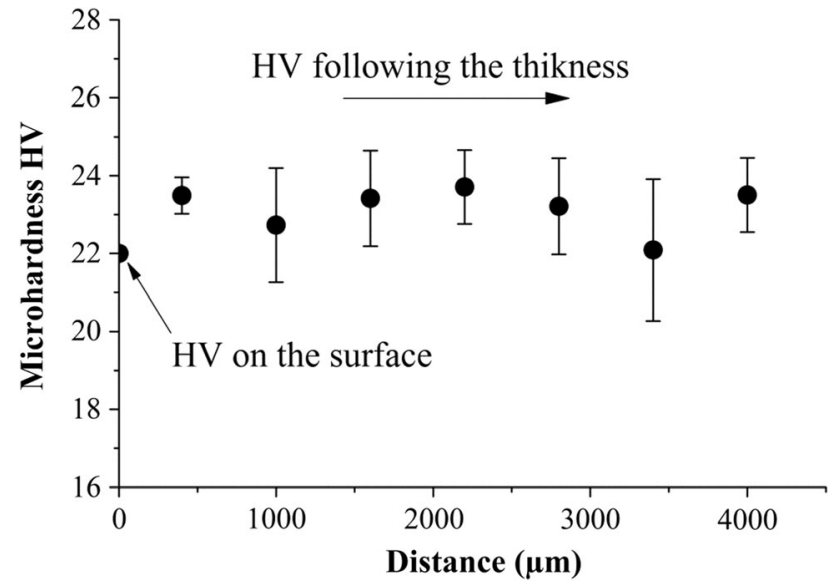

Fig. $8 \mathrm{HV}$ microhardness at the surface and along the thickness of the virgin PC sample

main chain have not undergone modification with UV aging.

\section{X-ray Diffraction}

Figure 6 shows the diffractogram of the virgin PC with three peaks of different angles and intensities whose values are reported in Table 2. The first, a fine peak located at 
$13.63^{\circ}$, reflects $\mathrm{X}$-ray diffraction by regularly arranged molecular chains. This shows that the material has ordered and periodic distribution zones of the chains representing crystallites. The two other peaks of lower intensities reveal reflections at large angles, indicating the existence of

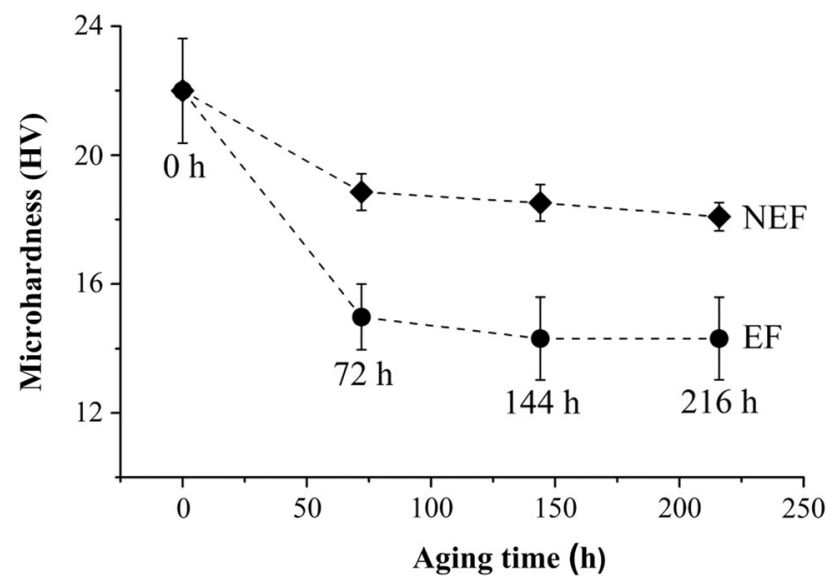

Fig. 9 Microhardness of the larger surfaces of the virgin and aged PC

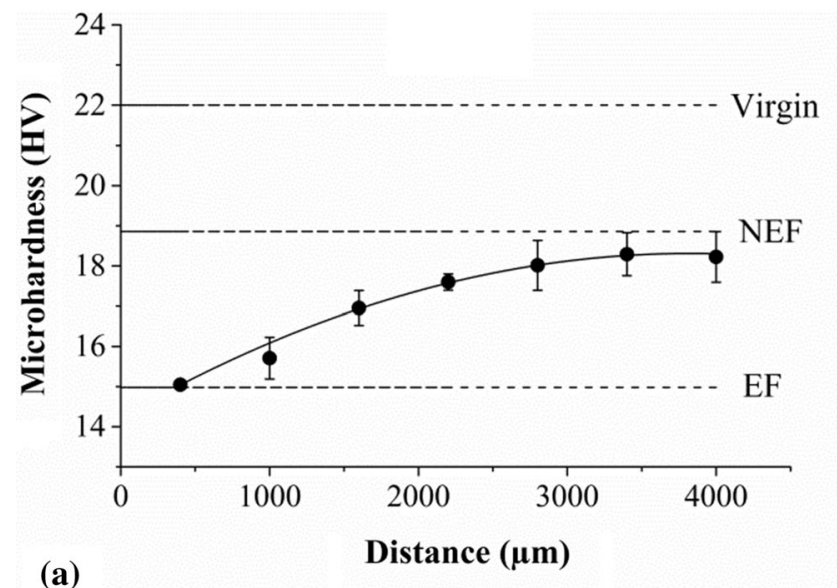

(a)

Distance $(\mu \mathrm{m})$

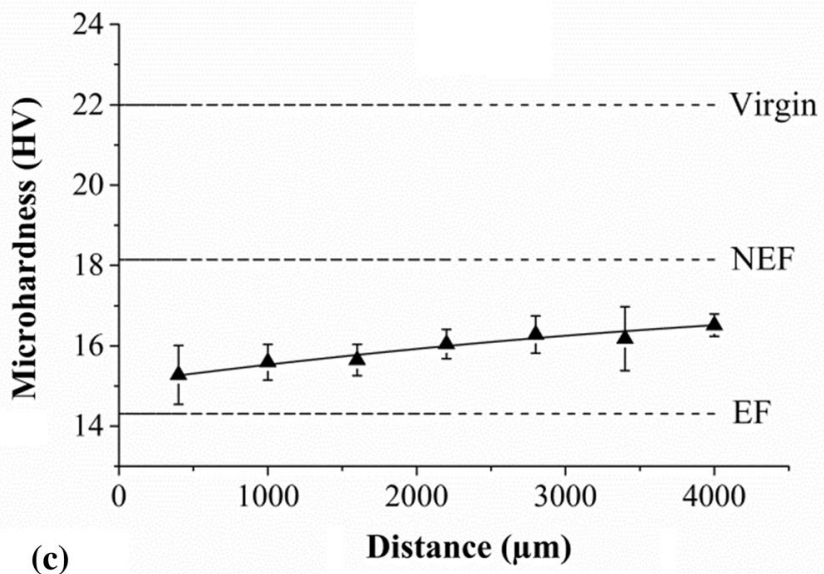

Fig. 10 Microhardness following the material thickness, for all UV exposure times: (a) $72 \mathrm{~h}$, (b) $144 \mathrm{~h}$ and (c) $216 \mathrm{~h}$ crystallites with smaller intermolecular distances (Table 2). These crystallites are relatively denser than those relating to the first peak.

The widths at mid-height of the peaks indicate that the sizes of the corresponding crystallites are very small. Scherrer's model [24] allowed the estimation of their mean value (Table 2):

$D=\frac{\lambda}{\beta \cos \theta}$

where $D$ is the crystallite size, $\beta$ is the integral width of the diffraction line, $\lambda$ is the wavelength of the X-ray beam and $\theta$ is the diffraction angle. The integral widths of the peaks were calculated by the EVA Diffract Plus software.

The aged samples were also analyzed by XRD to highlight the effect of aging on the microstructure. The superposition of the first diffraction peaks of all the studied samples is shown in Fig. 7 and their characteristics are reported in Table 3. The narrow form of the summits of these peaks suggests that the materials contain crystalline phases. In addition, it appeared that the intensity of the first peak, proportional to the degree of crystallinity, changes as

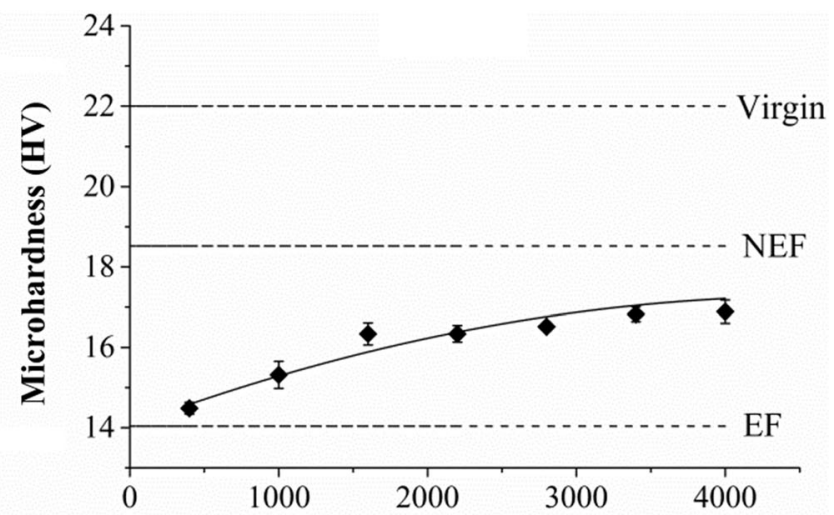

(b)

Distance $(\mu \mathrm{m})$ 


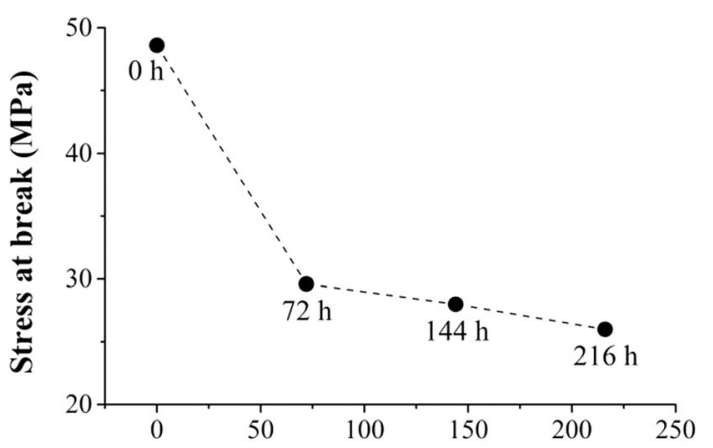

(a)

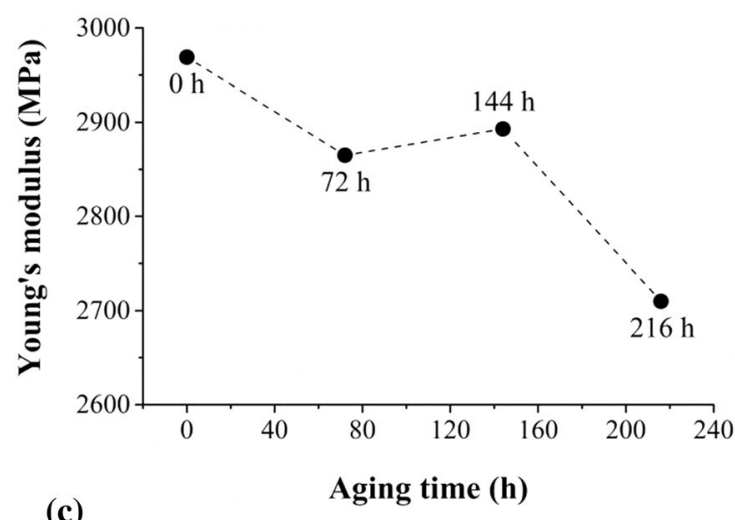

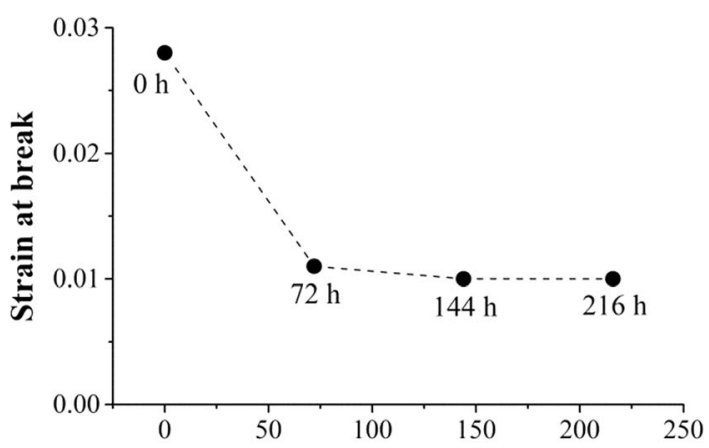

(b)

Aging time (h)

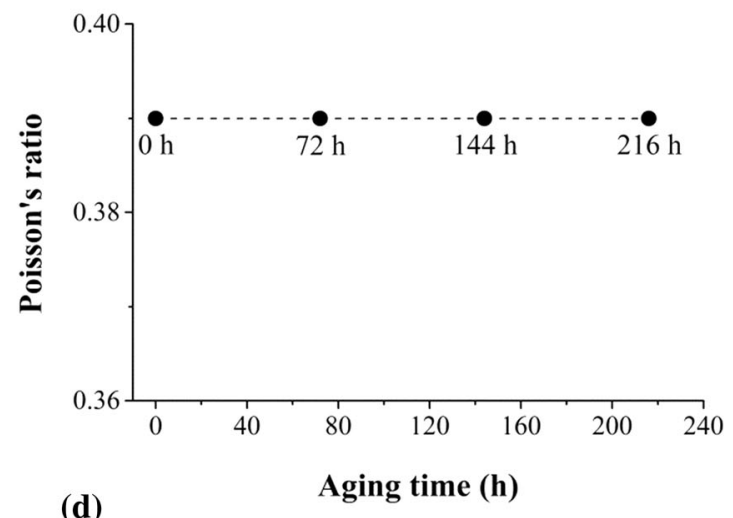

(d)

Fig. 11 Mechanical properties of the aged PC: (a) stress at break, (b) strain at break, (c) Young's modulus, (d) Poisson's ratio

Fig. 12 Fracture facies after tensile test of the virgin PC and $216 \mathrm{~h}$ aged PC
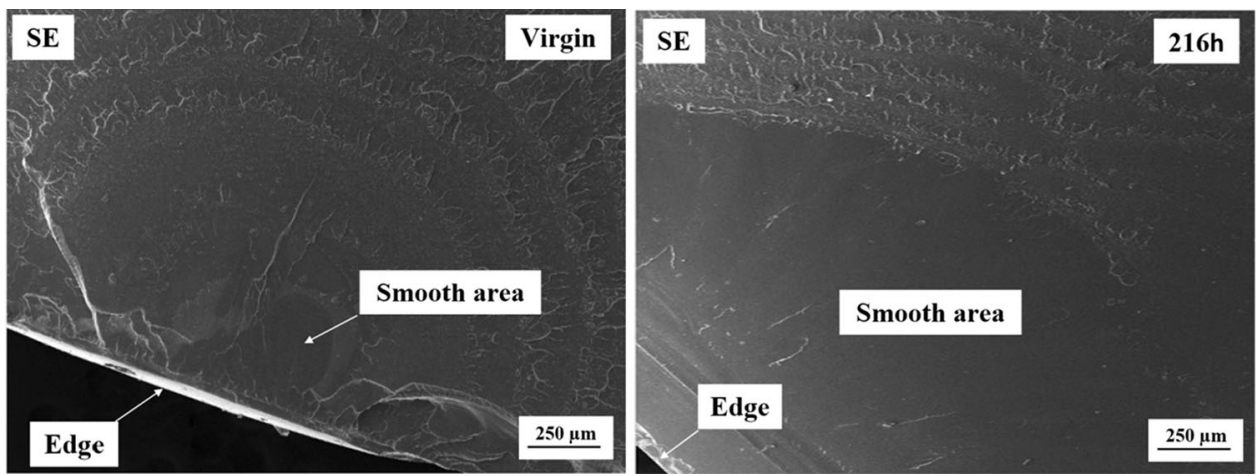

a function of aging time. This intensity is 26.2 a.u. for the blank PC while for the aging PC, it increases first to 36.8 a.u. for $72 \mathrm{~h}$ of aging and then decreases to $2.91 \mathrm{a}$.u. for $144 \mathrm{~h}$ of aging, and increases again to $40.4 \mathrm{a}$.u. for $216 \mathrm{~h}$ of UV exposure (Table 3). An offset of the line toward the large angles is also recorded, which is the result of a tightening of the molecular chains in the crystalline zones, following the rupture of the bridging between the chains under the action of the UV energy. This molecular chain reorganization contributes to the decrease in the interreticular distance of the crystallites and increases the crystallites size (Table 3 ). This result is in agreement with those of [25].
The most vulnerable bonds ( $\mathrm{C}-\mathrm{O}$ bonds) break and allow the chains to move, which causes a decrease in the crystallinity rate and an increase in the material amorphization, resulting in a decrease in the diffraction line's intensity. For long aging periods, free radicals can bind to each other or to chain residues, which contributes to the enhancement of the degree of crystallinity, confirmed by an increase in the diffracted intensity after UV irradiation. This is in agreement with the results of Hareesh et al. [26]. 


\section{Microhardness}

Five microhardness measurements were made on each of the larger faces of the samples and along their thicknesses. Figure 8 shows that the superficial microhardness of the virgin $\mathrm{PC}$ is $22 \mathrm{HV}$ and the microhardness along the specimen thickness is quite constant $(\sim 23 \mathrm{HV})$.

The average microhardness measured on a large surface of the virgin specimen and on the EF and NEF of the aged materials is reported in Fig. 9, as a function of the aging time. This figure shows that the microhardness of both faces is affected by UV radiation with a relatively large decrease in the EF. This suggests that the aged specimen is entirely affected by the UV radiations, which agrees with

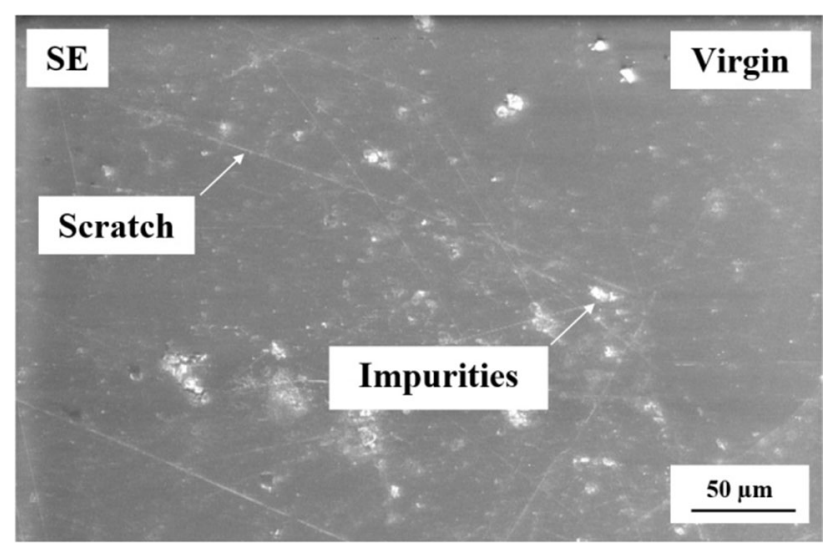

the UV-visible spectrophotometry analysis that highlighted a significant change in the absorbance and transmittance of the aged materials ("UV-Visible Spectrophotometry" section).

To analyze further the extent of the aging effect on the material, the microhardness was measured across the thickness of the aged PC samples. The results show a significant decrease in the microhardness along the thickness of the aged samples, confirming that UV aging affects the whole material (Fig. 10). However, for all the aging times, this decrease is more accentuated when approaching the specimen EF. Nevertheless, as shown in Fig. 10, microhardness following the thickness is lower as the aging time is higher and its variation has a polynomial trend for exposure durations of $72 \mathrm{~h}$ (Fig. 10a) and $144 \mathrm{~h}$ (Fig. 10b), while it becomes linear for $216 \mathrm{~h}$ (Fig. 10c).

\section{Tensile Properties}

Figure 11 shows that UV aging strongly affects the mechanical properties of PC. Indeed, the virgin material has stress at break and strain at break much greater than those of all aged materials (Fig. 11a, b). These properties drop significantly for $72 \mathrm{~h}$ aging time and tend to stabilize for longer UV exposure times. Indeed, the stress at break and strain at break decrease, respectively, of about $39 \%$ and $61 \%$, for the material aged for $72 \mathrm{~h}$. The decrease is, respectively, near $47 \%$ and $64 \%$ for $216 \mathrm{~h}$ aging time.

Fig. 13 SEM micrograph of the virgin PC

Fig. 14 OM micrographs of the UV aged PC: (a) $72 \mathrm{~h}$ and (b) $216 \mathrm{~h}$

Fig. 15 SEM micrographs of the UV aged PC: (a) $72 \mathrm{~h}$ and (b) $216 \mathrm{~h}$
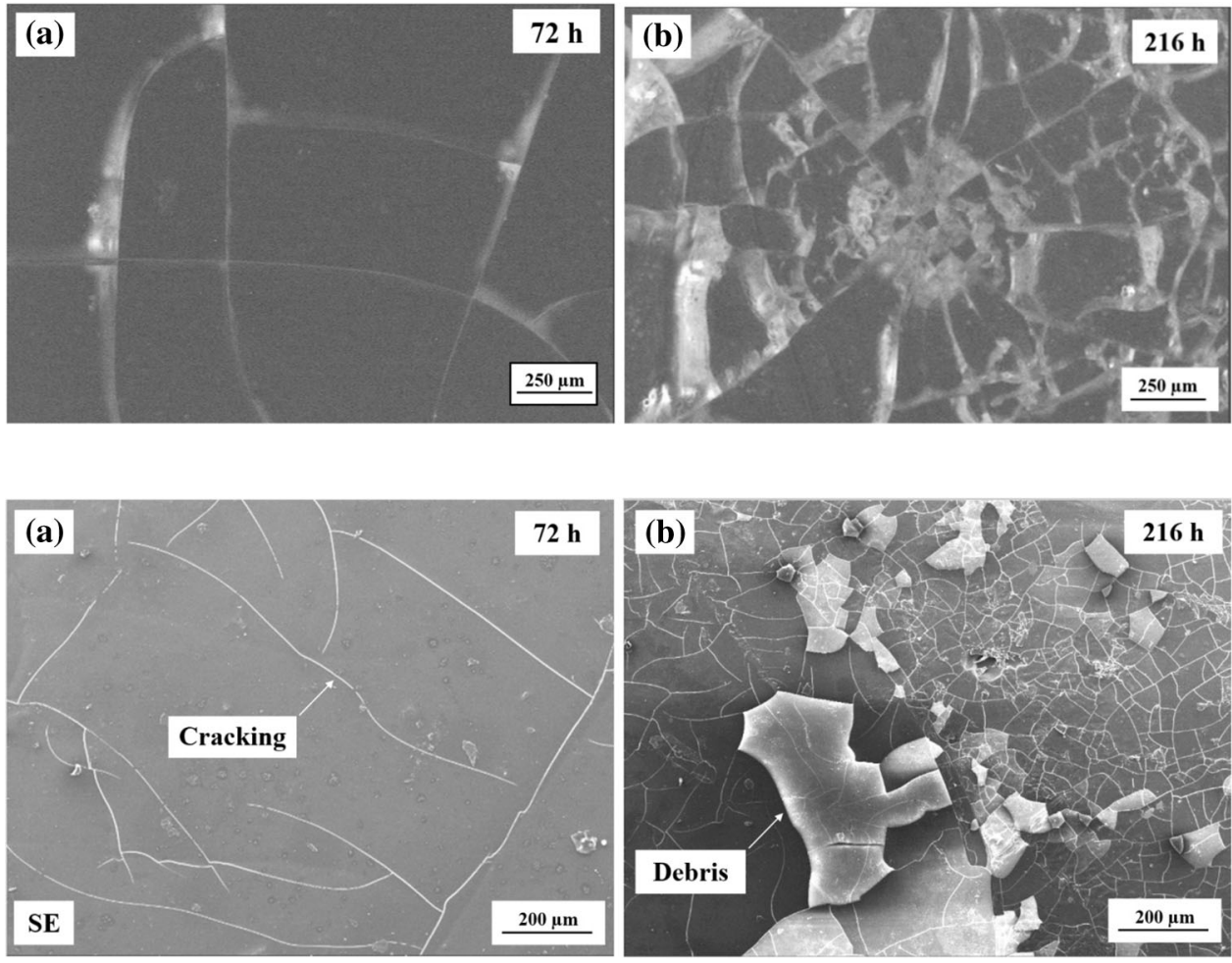


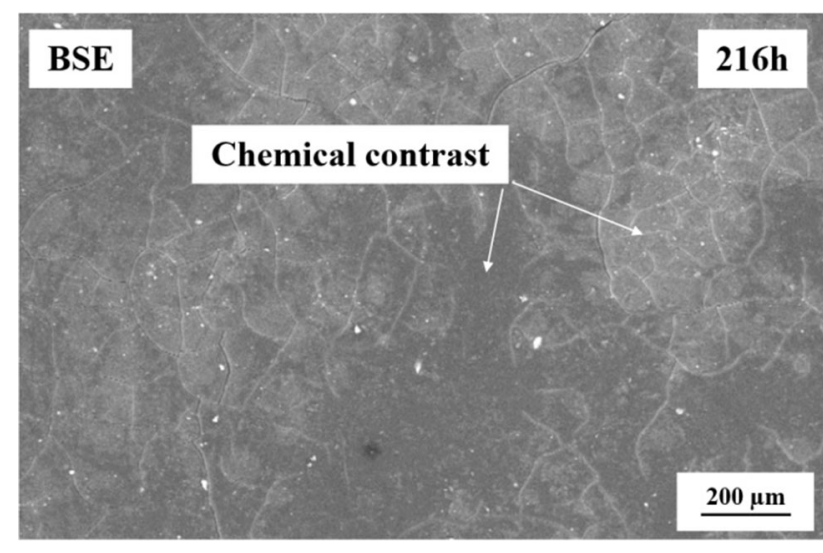

Fig. 16 BSE SEM micrograph of the UV aged $216 \mathrm{~h}$

The Young's modulus decreases of about 3.5\%, for UV exposure times of $72 \mathrm{~h}$ and $144 \mathrm{~h}$, as shown in Fig. 11c. A more significant decrease of approximately $9 \%$ is recorded for the longer aging time, i.e., $216 \mathrm{~h}$. The gradual decrease in the Young's modulus could be related to the rupture of the most vulnerable bonds, those of the carbonate serving as bridging to the molecular chains and thus ensuring an elasticity of the material.

The Poisson's ratio does not vary with aging time (Fig. 11d), which means that the isotropy/anisotropy property is not affected by UV irradiation.

Moreover, SEM micrographs of fracture facies reveal a larger smooth area for the aged materials than for virgin PC (Fig. 12), proving that the UV aging makes it more brittle than the studied material, which is in agreement with the results reported in the literature $[10,22]$.

\section{Microstructures}

To understand better the decreases in mechanical properties of the PC discussed above, micrographic observations were made on the surfaces of the blank and aged PC. The SEM micrographs of the virgin material show superficial scratches and impurities due to handling during delivery (Fig. 13).

Figure 14 shows the OM micrographs of EF of the samples aged during $72 \mathrm{~h}$ and $216 \mathrm{~h}$. These micrographs show cellular cracking whose extent becomes larger for long periods of UV exposure. Such cellular cracking was also observed in SEM micrographs that moreover reveal detachment of cells for $216 \mathrm{~h}$ aged material (Fig. 15).

The interaction between UV and PC begins with an excitation of the material molecules. The frequency and amplitude of molecular vibration depend on the UV radiation wavelength. The bonds of the carbonate group that are the most vulnerable begin to break and the material damage starts with initiation of microcracks which grow as the aging time increases. The breaking of these bonds can lead to the formation of free radicals which can bind each other or with other molecular chains, initiating the crosslinking phenomenon $[9,10]$.

The microstructure observations highlighted a damage of the EF of the aged PC. In addition to the chemical bonds breaking, the presence of superficial cracks (Figs. 14 and 15) gives rise to a concentration of stresses causing the sudden rupture of the material, which could explain the embrittlement and thus the decrease in the mechanical properties of the aged material.

SEM micrograph of the sample surface obtained by BSE mode (Fig. 16) shows a chemical contrast that is more marked near the cracks, indicating a relative increase in molecular weight in these zones. Indeed, the splitting of the molecular chains under the UV aging generates a redistribution of the molecular weight by migration of free radicals and by rearrangement of the chains. This result agrees with DRX finding which suggested a tightening of the molecular chains.

\section{Conclusion}

In this work, effects of the UV aging on the properties of a PC were studied. It appeared that UV radiations influence the optical properties of the material by decreasing its transparency. FTIR analyses revealed the breaking of vulnerable bonds, reducing the elasticity of the aged material. This leads to a rearrangement of the molecular chains and a change in the size of the crystallites, as suggested by XRD investigations. A decrease in microhardness through the thickness proved a gradual deterioration in the depth. Tensile tests showed embrittlement and decrease in mechanical properties of the aged material. OM and SEM observations highlighted cell cracking representing stress concentration zones that are probably at the origin of the embrittlement of the aged materials. Fracture facies examined by SEM confirmed the fragile behavior induced by UV exposure.

As main conclusion, UV radiations cause breaking of vulnerable chemical bonds, allowing a new reorganization of the molecular chain's network, which leads to a decrease in physical and mechanical properties of PC.

Acknowledgments The authors thank the management of the National Institute of Applied Sciences (INSA de Blois) for providing the material.

\section{References}

1. B.T. Anthony, Lexan polycarbonate for automotive forward lighting. Mater. Des. 6(6), 293-302 (1985) 
2. T. Sharma, S. Aggarwal, A. Sharma, S. Kumar, V.K. Mittal, P.C. Kalsi, V.K. Manchanda, Modification of optical properties of polycarbonate by gamma irradiation. Radiat. Eff. Defects Solids 163(2), 161-167 (2008)

3. W.A. MacDonald, M.K. Looney, D. MacKerron, R. Eveson, R. Adam, K. Hashimoto, K. Rakos, Latest advances in substrates for flexible electronics. J. Soc. Inf. Disp. 15(12), 1075 (2007)

4. G.E. Blanford, R.M. Walker, J.P. Wefel, Calibration of plastic track detectors for use in cosmic ray experiments. Radiat. Eff. 5(1), 41-45 (1970)

5. L. Piraux, S. Dubois, S. Demoustier-Champagne, Template synthesis of nanoscale materials using the membrane porosity. Nucl. Instrum. Methods Phys. Res. Sect. B Beam Interact. Mater. Atoms 131(1-4), 357-363 (1997)

6. J. Jagielski, A. Turos, D. Bielinski, A.M. Abdul-Kader, A. Piatkowska, Ion-beam modified polymers for biomedical applications. Nucl. Instruments Methods Phys. Res. Sect. B Beam Interact. Mater. Atoms 261(1-2), 690-693 (2007)

7. K.C.C. Tse, F.M.F. Ng, K.N. Yu, Photo-degradation of PADC by UV radiation at various wavelengths. Polym. Degrad. Stab. 91(10), 2380-2388 (2006)

8. H.M. Zidan, A. Tawansi, M. Abu-Elnader, Miscibility, optical and dielectric properties of UV-irradiated poly(vinylacetate)/ poly(methylmethacrylate) blends. Phys. B Condens. Matter 339(2-3), 78-86 (2003)

9. M. El-Ghazaly, A. Sh Aydarous, T.A. Al-Thomali, Ultraviolet radiation of short wavelength (UVC) induced-modifications in optical properties of PADC. Life Sci. J. 10(4), 2446-2450 (2013)

10. S. Eve, J. Mohr, Study of the surface modification of the PMMA by UV-radiation. Proc. Eng. 1(1), 237-240 (2009)

11. M. El-Ghazaly, A.A. Alzahrani, Correlation between photoluminescence and optical properties of Makrofol ${ }^{\circledR}$ De 1-1 exposed to high flux of UVC. Radiat. Eff. Defects Solids 168(2), 137-145 (2013)

12. Y.A. Aggour, M.S. Aziz, Degradation of polyacrylonitrile by low energy ion beam and UV radiation. Polym. Test. 19(3), 261-267 (2000)

13. A. Factor, "Mechanisms of Thermal and Photodegradations of Bisphenol A Polycarbonate," in Polymer Durability, vol. 249, no. Scheme I, pp. 59-76 (1996)

14. A. Rivaton, D. Sallet, J. Lemaire, The photochemistry of bisphenol-A polycarbonate reconsidered. Polym. Photochem. 3(6), 463-481 (1983)
15. A. Torikai, T. Mitsuoka, K. Fueki, Wavelength sensitivity of the photoinduced reaction in polycarbonate. J. Polym. Sci. Part A: Polym. Chem. 31(11), 2785-2788 (1993)

16. J. Lemaire, J.L. Gardette, A. Rivaton, A. Roger, Dual photochemistries in aliphatic polyamides, bisphenol A polycarbonate and aromatic polyurethanes-a short review. Polym. Degrad. Stab. 15(1), 1-13 (1986)

17. A. Rivaton, Recent advances in bisphenol-A polycarbonate photodegradation. Polym. Degrad. Stab. 49(1), 163-179 (1995)

18. D.T. Clark, M.M. Abu-Shbak, Surface aspects of the heat treatment of polyethylene terephthalate as revealed by ESCA. Polym. Degrad. Stab. 9(4), 225-237 (1984)

19. A. Factor, M.L. Chu, The rôle of oxygen in the photo-ageing of bisphenol-A polycarbonate. Polym. Degrad. Stab. 2(3), 203-223 (1980)

20. E. Ghorbel, I. Hadriche, G. Casalino, N. Masmoudi, Characterization of thermo-mechanical and fracture behaviors of thermoplastic polymers. Materials (Basel) 7(1), 375-398 (2014)

21. K.A. Zimmerman, S.C. Langford, J.T. Dickinson, R.P. Dion, Electron and photon emission accompanying deformation and fracture of polycarbonate. J. Polym. Sci. Part B Polym. Phys. 31(9), 1229-1243 (1993)

22. N.S. DeMelo, R. Pondé Weber, J.C. Miguez Suarez, Toughness behavior of gamma-irradiated polycarbonate. Polym. Test. 26(3), 315-322 (2007)

23. A. Rivaton, B. Mailhot, J. Soulestin, H. Varghese, J.L. Gardette, Comparison of the photochemical and thermal degradation of bisphenol-A polycarbonate and trimethylcyclohexane-polycarbonate. Polym. Degrad. Stab. 75(1), 17-33 (2002)

24. A.L. Patterson, The Scherrer formula for X-ray particle size determination. Phys. Rev. 56(10), 978-982 (1939)

25. Z. Tang, C. Youshuang, W. Mouhua, Specific properties improvement of polycarbonate induced by irradiation at elevated particular temperature. Radiat. Phys. Chem. 96, 171-175 (2014)

26. K. Hareesh, A.K. Pandey, Y. Sangappa, R. Bhat, A. Venkataraman, G. Sanjeev, Changes in the properties of Lexan polycarbonate by UV irradiation. Nucl. Instrum. Methods Phys. Res. Sect. B Beam Interact. Mater. Atoms 295, 61-68 (2013)

Publisher's Note Springer Nature remains neutral with regard to jurisdictional claims in published maps and institutional affiliations. 